\title{
The effect of caregiver training in increasing social interaction and contact time with children living in residential care facilities
}

\author{
Lyndsay Koch, BSc OT, MSc OT (Wits) \\ Lecturer, Department of Occupational Therapy, School of Therapeutic Sciences, Faculty of Health Sciences, University of the \\ Witwatersrand
}

\section{Denise Franzsen, BSc OT(Wits), MSc OT(Wits), PhD (Wits)}

Senior Lecturer, Department of Occupational Therapy, School of Therapeutic Sciences, Faculty of Health Sciences, University of the Witwatersrand

Infants and toddlers living in residential care facilities are at risk of developmental delay. Environmental factors contributing to this risk are the temporal context (how children spend their time) and social context (how and when caregivers interact with the children). This study compared time-use patterns of children living in residential care facilities where caregiver training had previously taken place versus those in facilities where caregiver training had not taken place using a non-experimental, cross sectional static group comparison study design. Spot observations were used to estimate time-use patterns of infants and toddlers living in residential care facilities in Johannesburg.

Results show that caregiver training positively changed the quantity of the time that infants spent with their caregivers (temporal context) and the quality of time toddlers spent with their caregivers (social context). Thus caregiver training has the potential to improve the environment in residential care facilities and can be used as an intervention strategy by occupational therapists.

Key words: Residential care facilities, time-use patterns, caregiver training, quantity of time spent caregiving, quality of time spent caregiving

\section{INTRODUCTION AND LITERATURE REVIEW}

Institutional care is a reality around the world for children whose biological families cannot or will not care for them. Within South Africa, high unemployment rates and associated poverty together with high HIV infection rates and disease have created a large population of vulnerable children that must be cared for outside of the normal extended family structures'. In developing countries around the world ${ }^{2}$ numerous residential care facilities that provide full-time care for children whose biological families cannot care for them have been created to cope with this burgeoning population.

These residential care facilities have long been associated with negative developmental outcomes ${ }^{3-5}$. Appropriate early childhood development forms a crucial base for later skill development and is influenced by a myriad of biological and environmental factors ${ }^{6}$. Moore in a review in $2002^{7}$ listed the characteristics or principles of early human brain development of young children who spend their early years exposed to an unstimulating, unsupportive environment and the advesre ways in which this can be affected, resulting in cognitive and social delays. Human development is reliant on experience and is thus related to both direct and indirect input from the environment. Social interactions (or mothering) with one, or a small group, of primary caregivers, appears to be the most important environmental factor in supporting appropriate childhood development ${ }^{7}$. Yet researchers around the world report that caregivers within residential care facilities have little time for interaction with the children in their care and appear to be cold, clinical and unresponsive to the emotional needs of the children ${ }^{2,8,9}$.

These caregivers are important in creating a social and temporal context that is conducive to early development. In 2008, Tirella et al. ${ }^{10}$ confirmed that the lack of interaction in child residential facilities in Russia was due to the lack of time that was spent in contact with the caregivers or the inadequate temporal context of infants and toddlers. They found that when awake, infants spent up to $65 \%$ and toddlers up to $43 \%$ of their time without any human interaction. Observations within the facilities showed that the caregivers completed care giving activities such as feeding and bathing, as quickly as possible with few interactions and minimal touch. This time use or temporal context for infants and toddlers in residential care facilities seems to be fairly common around the world and is associated with rotational shift work, poor resources, staff shortages and the expectation that tasks outside of direct child care be completed ${ }^{11,12}$. McCall et al. ${ }^{13}$ also reported that due to the rotation and high staff turnover, a child may see 50 - 100 different caregivers before the age of two years. The social context which then lacks the characteristics of warm, responsive care giving is affected by the child's temporal context which lacks time spent in human interaction $7,14,15$.

Inadequate temporal and social contexts have been shown to contribute to devastating impairments in the social and emotional development of these children, affecting their ability to form and maintain lasting relationships within society ${ }^{4,7,9}$. Research and practice indicate that effective intervention can make a significant difference to the developmental trajectories of these at-risk children ${ }^{16}$.

However with limited resources these interventions need to reach a large number of children and need to address the creation of experiences that positively enhance development. There is a growing body of literature that suggests that programmes which meet these criteria should include formal caregiver training which supports the implementation of relationship building ${ }^{17-19}$. This type of intervention has been found to increase responsive caregiving and social interactions with the children resulting in positive changes to the social and temporal context of children living in residential care facilities. This results in an improvement in their verbal skills including increased conversations, animated emotional responses and positive social interactions as well as overall development ${ }^{18,20}$. These findings were confirmed in a study by the Infant Care Facility 
Improvement Project in 2014 in Nepal where caregivers received formal training which encouraged them to make changes in their interaction patterns with the infants that they cared for in residential facilities ${ }^{19}$. Caregivers were required to focus more on the socio-emotional and cognitive developmental needs of the infants by making sustained eye contact when feeding, changing nappies and bathing the children.

Evaluating the effectiveness of the caregiver training in relation to the children's context in the short term is difficult and Groark and her colleagues in $2005^{20}$ and $20 \mathrm{I} \mathrm{I}{ }^{21}$ reported that most studies used informal observation of improvement in the children's context and behaviour ${ }^{20,21}$.

The purpose of the study reported on in this paper was to evaluate the caregiver training offered by the Thusanani Children's Foundation in the residential care facilities by formalising the observation of:

* the time-use or temporal context and

* the one-on-one interaction or social context

of infants and toddlers in residential care facilities where caregiver training had and had not taken place.

\section{METHOD}

A quasi-experimental static group comparison study with a crosssectional design was used to study the impact of a caregiver training programme. This study did not include the design and implementation of caregiver training at the residential care facilities.

In order to assess the temporal and social contexts of the children, spot observations were used which allowed information to be collected in a natural setting ${ }^{22}$. Spot observations are a specific form of passive objective observation which involves an impartial observer watching a specific individual for a set time to determine his/her behaviour during that time. They are regular, unannounced observations that are used to estimate overall time-use of an individual which provides quantitative data. Spot observations have been cited as a reliable method of gaining information about how children spend their time as it does not rely on individuals to provide the correct information ${ }^{22,23}$. This methodology has been used in two previous time-use studies to observe contexts in residential care facilities ${ }^{10,23}$.

\section{Study sites and caregiver training}

The sites for the study were six child residential care facilities in Johannesburg recruited from the joint adoption clinic based at The Child Memorial Institute for Children in Johannesburg. One of the partners in the clinic is the Thusanani Children's Foundation, an NGO which identifies and provides occupational therapy intervention for children who are disabled or developmentally delayed living in residential care facilities. The organisation provides occupational therapy services as well as training for the care givers in the homes.

At the time of the study, Thusanani Children's Foundation had completed caregiver training programmes of between three and six months at three residential care facilities. The programme consisted of six three-hour sessions conducted over a period of six weeks presented at each facility by an occupational therapist. his meant that the maximum number of caregivers at any one facility could attend and that caregivers who work together on a daily basis could share knowledge and skills. Furthermore, by offering training on site, the modelling of skills and activities could be done with the children from the facility, with the therapist adapting the material to suit the individual needs of the children at that facility. Training combined theoretical knowledge about child development with practical skills training. Developmental activities that could be used during personal management time were modelled by the therapist and caregivers were encouraged to observe, participate and take over the execution of these activities. Considerable time was spent in practical sessions where caregivers practiced simple stimulation activities that could be used during interactions with children when performing personal management activities. For example, bath-time could be turned into a play activity with infants and toddlers learning about their bodies, about water and the concepts of 'wet' and 'dry'. Although the material was presented in English, pictures, photos, demonstration and translation were used to overcome the difficulties of language and low educational levels.

\section{Sampling}

Three facilities where caregiver training had been completed agreed to participate in the study (Group I). These facilities were matched to three similar residential care facilities (Group 2) where care givers had not been trained. Each group had one facility classified as large ( $>$ I 8 children), privately funded and well-resourced (volunteers $>$ once a week and plenty of toys), one facility classified as medium ( I 2- I 8 children), government funded with average resources (volunteers < once a week and toys limited) and one facility classified as small ( $<12$ children), government funded and poorly resourced (no volunteers and $<$ one toy per child). All the facilities were classified as "baby homes" that provided 24-hour care for children between the ages of 0 months and 24 months who had been abandoned, orphaned or removed from their biological families. The average child to caregiver ratio ranged from 5:I to $7: 1$.

Altogether 60 infants (0-12 months) and toddlers (I 2-24 months) were randomly selected for observation. In order to achieve a spread of different ages, a stratified sampling method was used and 10 children from each facility were selected: five infants and five toddlers. In total the sample consisted of I 4 infants and 16 toddlers in Group 2 (as only four infants were available at one facility), living in residential care where no caregiver training had occurred and 15 infants and I5 toddlers in Group I, living in residential care where caregiver training had taken place.

\section{Measurement tool}

One-minute, spot observations were used in this study for each child participant, where the child's actions and contact with a caregiver, another adult or another child in that minute was scored on a checklist. Observations were made on:

* what the child was doing (activities) or their temporal context; * if they were with someone and who this person was as well as what they were doing and whether any language interactions were occurring (which constituted the child's social context).

Items and scoring options are presented in Table I on page 48.

\section{Research Procedure}

Ethical clearance for the study was obtained from the HREC at the University of the Witwatersrand (M0806 I4) and permission to use the facility for research was obtained from the managers of the care facilities who also signed informed consent for the children's participation in the study. Caregivers were provided with an information sheet about the study and they signed informed consent as they were present with the children during the observations. The caregivers understood that the researcher was observing and scoring the children's temporal and social context and not evaluating the caregivers' job performance.

The researcher entered the room where the children were cared for and observed each participant for one minute in a random order. Five children were assessed at a time and the observation for each child was scored on the checklist (cf. Table I). When each of the five participants had been scored the researcher left the room and returned every half hour to observe the children again over an eight-hour period. When in the room the researcher did not make eye-contact or interact with either the children or the caregivers in any way. Participating caregivers did not know which five children were being observed. This was to try to prevent changes in caregiver behaviour which could have unduly influenced the results. Different residential care facilities were assessed on different days. The observer was stationed away from the room in the 20 minutes between observations. 
Table I: Data Codes

\begin{tabular}{|c|c|c|}
\hline \multicolumn{3}{|c|}{ Determined by the immediate presence of an adult and whether the target child is engaged with that person } \\
\hline ALONE & $\begin{array}{l}\text { Not engaged in any interactions. } \\
\text { NB Sitting in caregiver's laps facing away from her while caregiver is doing } \\
\text { something else (e.g. speaking to another caregiver) is still considered } \\
\text { alone. }\end{array}$ & $\mathrm{Al}$ \\
\hline WITH CAREGIVER & Child actively engaged with primary caregiver. & $\mathrm{A} 2$ \\
\hline WITH ANOTHER ADULT & $\begin{array}{l}\text { Child actively engaged with an adult. } \\
\text { Adult is NOT primary caregiver (e.g. doctor, volunteer). }\end{array}$ & A3 \\
\hline WITH ANOTHER CHILD & $\begin{array}{l}\text { Child actively engaged with another child. } \\
\text { NB Not parallel play. }\end{array}$ & A4 \\
\hline \multicolumn{3}{|c|}{ Refers to activity in which the child is engaged } \\
\hline PERSONAL MANAGEMENT ACTIVITIES & $\begin{array}{l}\text { Includes the following: } \\
\text { Feeding } \\
\text { Changing } \\
\text { Toileting } \\
\text { Dressing } \\
\text { Transitions from one activity to another }\end{array}$ & $\mathrm{BI}$ \\
\hline MEANINGFUL / PURPOSEFUL ACTIVITY (PLAY) & Developmentally appropriate tasks or learning-based tasks. & B2 \\
\hline NON-MEANINGFUL ACTIVITY & $\begin{array}{l}\text { Developmentally inappropriate activities e.g.: } \\
\text { wandering around the room. } \\
\text { inappropriate sucking or banging of toys. } \\
\text { repetitive movements such as rocking. }\end{array}$ & B3 \\
\hline SLEEP & Child visibly asleep. & B4 \\
\hline \multicolumn{3}{|c|}{$\begin{array}{l}\text { ADULT ROLE } \\
\text { Refers to the supervision structure }\end{array}$} \\
\hline NO MONITOR & No adult in the room. & $\mathrm{Cl}$ \\
\hline MONITOR & $\begin{array}{l}\text { Adult in the room. } \\
\text { Not actively engaged with target child. } \\
\text { Not actively engaged with other children in the room. }\end{array}$ & $\mathrm{C} 2$ \\
\hline ADULT LEAD & $\begin{array}{l}\text { Adult in the room. } \\
\text { Leading an activity or engaged with children. }\end{array}$ & $\mathrm{C} 3$ \\
\hline ONE-ON-ONE & $\begin{array}{l}\text { Adult in the room. } \\
\text { Providing one-on-one attention to target child. } \\
\text { This is determined by either making eye-contact, touching the child in a } \\
\text { purposeful way or vocalizing to the child. }\end{array}$ & C4 \\
\hline \multicolumn{3}{|c|}{ Refers to whether target child is speaking or being spoken to, as well as general language in the room } \\
\hline ADULT LANGUAGE & $\begin{array}{l}\text { Adult speaking to target child. } \\
\text { Adult speaking to group of children. } \\
\text { Adult speaking to another adult. } \\
\text { Adult not speaking at all. }\end{array}$ & $\begin{array}{l}\text { D1 } \\
\text { D2 } \\
\text { D3 } \\
\text { D4 }\end{array}$ \\
\hline CHILD LANGUAGE & $\begin{array}{l}\text { Target child talking/ cooing/ babbling to an adult. } \\
\text { Target child talking/ cooing/ babbling to self or toy. } \\
\text { Target child speaking to another child. } \\
\text { Target child quiet. }\end{array}$ & $\begin{array}{l}\text { EI } \\
\text { E2 } \\
\text { E3 } \\
\text { E4 }\end{array}$ \\
\hline
\end{tabular}

\section{Data analysis}

To determine the temporal or time-related context for the children, the total number of observations made over the day were separated into specific activities as outlined in Table $I$. This allowed time-use patterns or the temporal context in the form of activity profiles representing the mean percentage of time spent in different activities for children in Group I and Group 2 to be generated and compared.

The social context was analysed by calculating the mean time spent alone for infant and toddlers or in one-on-one contact with a caregiver, another adult or another child (Table I). The quality and number of interactions in terms of one-on-one and language interaction with the caregiver or another adult or child was also considered. All sleep observations were removed from the data for this analysis as children were expected to be alone and not socialising when asleep.

The Mann-Whitney $\cup$ Test was used to establish statistical differences between the Group I and Group 2 for the temporal and social factors using Staistica V I3.2 software.

\section{RESULTS}

\section{Demographic information}

A total of 26 caregivers and 60 infants and toddlers from six residential care facilities participated in this study. The caregivers were all female and their age ranged between 18 years and 49 years with 
a mean age of 35.9 years (SD 9.02). Caregiver experience ranged between 0 years and II years with a mean of 3.3 years (SD 2.87). Observations were made on 30 children, both toddlers and infants in each of the two groups. The infants ranged in age from 3 months to 12 months with a mean age of 7.4 months (SD 2.7). The toddlers ranged in age from I3 months to 23 months with a mean age of 16.8 months. There were no significant differences in demographics between the participants in Group I and Group 2.

\section{Temporal context of children (time-use during the day)}

Activity profiles indicating the mean percentage of time spent in personal management, meaningful activity, non-meaningful activity and sleep for infants and toddlers indicated very little difference between Group I and Group 2 (see Figure I).

Although the infants in Group I (where the caregivers had received training) spent more time in personal management activities, although this difference was not significant $(p>0.05)$. The time the children spent on different activities when observed during the day was similar for Group I and Group 2, thus caregiver training appears to have no effect on the temporal context of the children during the day.

The data for time spent alone and time spent in one-on-one contact with a primary caregiver are summarised in Figure 2.

There was a significant reduction in time spent alone without any interactions in the infant group $(p<0.05)$ and a significant increase in time spent in one-on-one contact with a primary caregiver $(p<0.00 I)$ for Group I. These infants living in residential care facilities where caregiver training had taken place spent $17.2 \%$ less time alone and $17 \%$ more time in interactions with their primary caregivers than those in Group 2 (living in facilities where caregiver training had not taken place). The differences in the toddler group were not as large, but were still significant. Toddlers in Group I, living in residential care facilities where caregiver training had taken place spent $10.5 \%$ less time alone $(\mathrm{p}<0.0 \mathrm{I})$ and $12.6 \%$ more time in oneon-one contact with their primary caregivers $(p<0.00 \mathrm{I})$. Interactions with another adult or another child made up the remainder of the observations, but were highly variable and did not significantly contribute to between-group differences.

\section{Social context of children (human interactions in the environment)}

The caregiver training had emphasised the importance of social contact during the time when personal management activities such as feeding, bathing or dressing were carried out. Caregivers were encouraged to use this time for interaction with the children and to speak to them throughout the activity. Thus observations made during these activities were analysed separately. The time spent alone (i.e. drinking from a bottle propped on a pillow in the infant's cot) versus social contact with

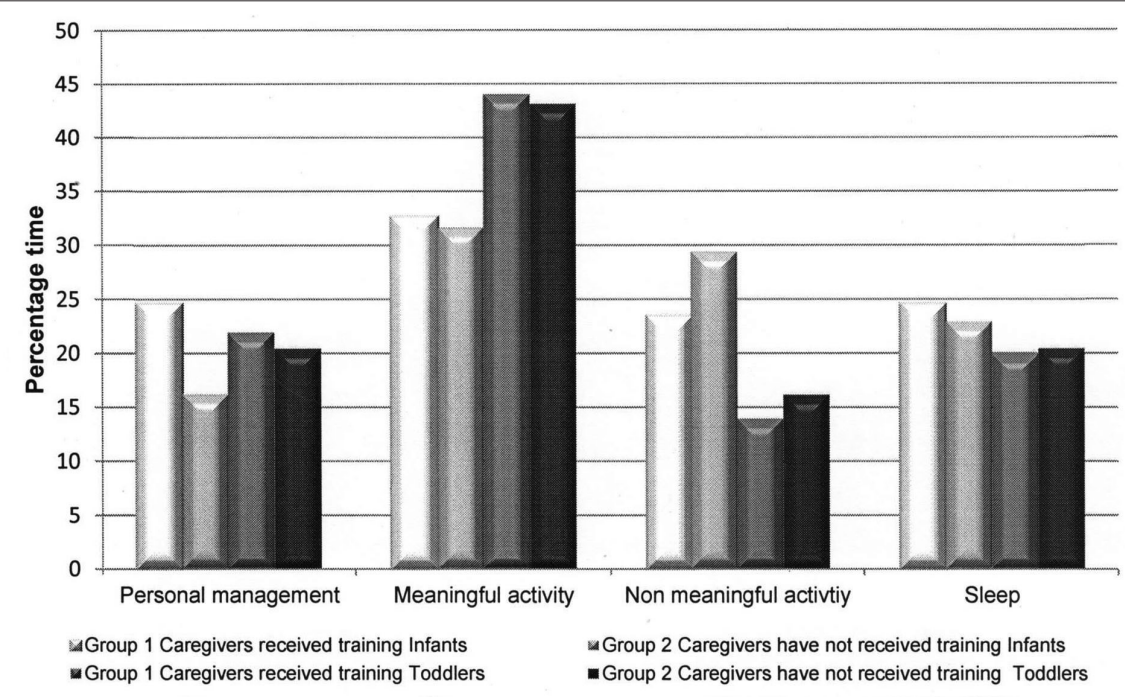

Figure I: Temporal context of infants and toddlers in groups where the caregivers had and had not received training

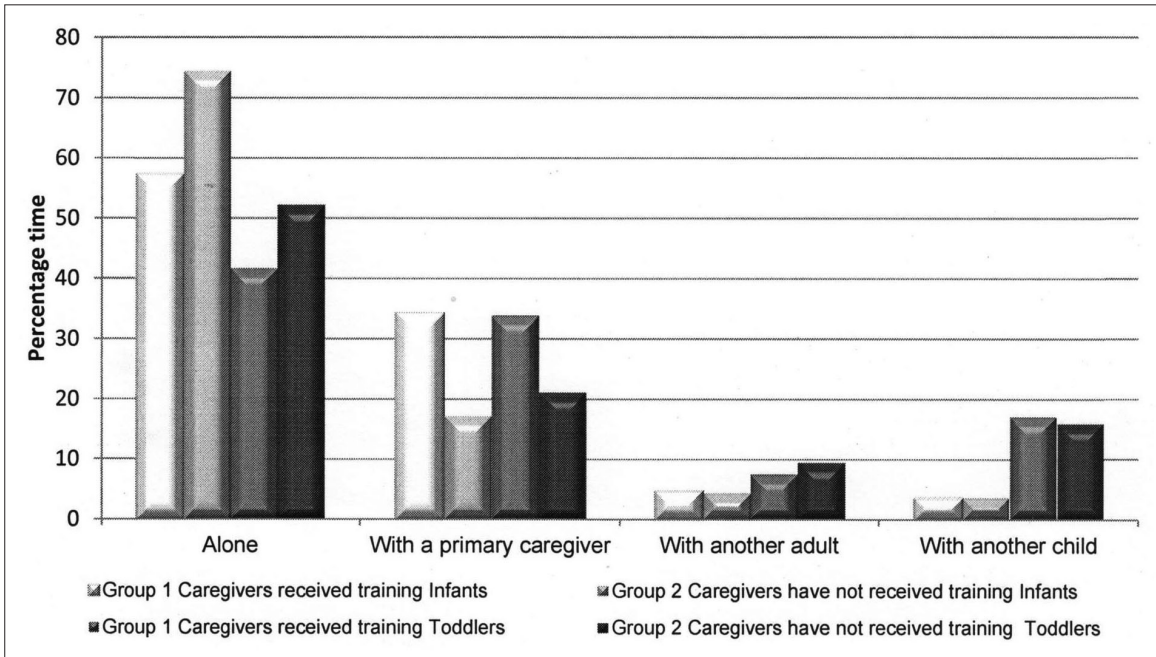

Figure 2: Time infants and toddlers spent alone, with a caregiver, another adult or another child when not asleep in groups where the caregivers had and had not received training

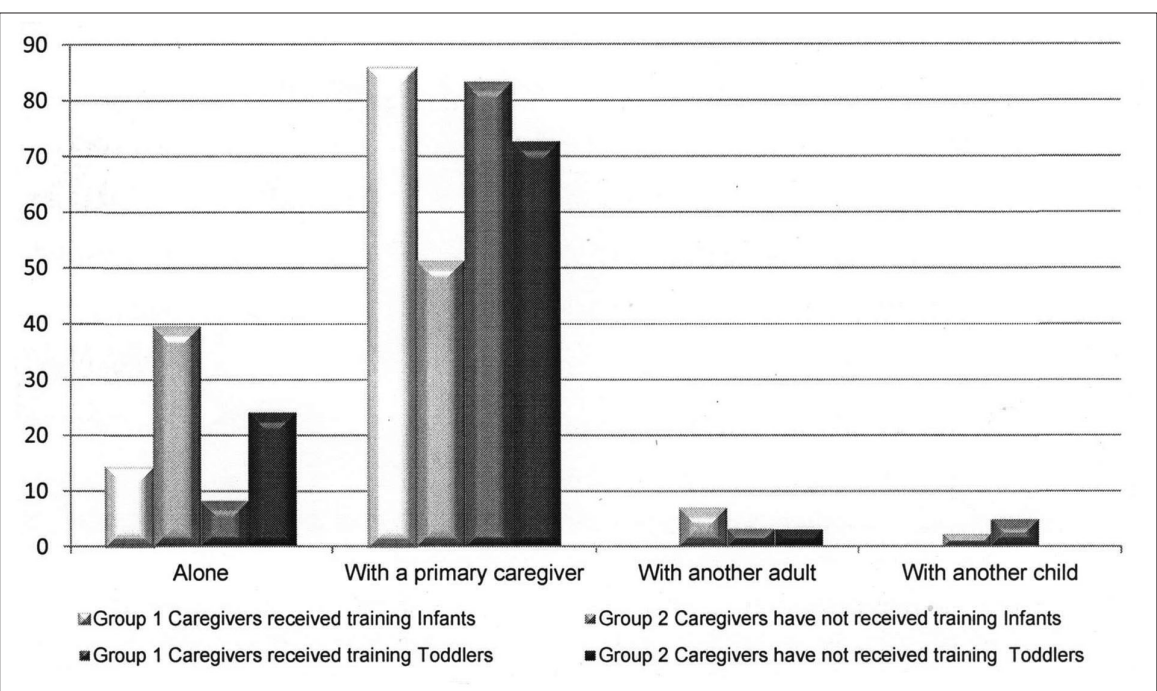

Figure 3: Time child spent alone or in in social contact with a caregiver, another adult or another child during personal management activities in groups where the caregivers had and had not received training the child during personal management activities (infant held and talked to while feeding) is indicated in Figure 3. 
There was a significant increase in time spent in one-on-one contact with a primary caregiver during personal management activities in Group I for both the infants $(p<0.00$ I) and toddlers $(p<0.00 \mathrm{I})$. Infants in Group I where caregivers had received training spent $34.5 \%$ more time interacting with a primary caregiver during personal management activities than those in Group 2.

The greatest difference for children in Group I where caregiver training had occurred was seen in the language use of caregivers. Trained caregivers spent $44.9 \%(p<0.00 I)$ more time using verbal language during personal management activities with infants, and $41.0 \%(p<0.00 I)$ more time vocalising with toddlers, than the caregivers in Group 2 (Figure 4).

There was also a significant difference in the time infants and toddlers spent babbling, cooing or talking to their caregivers between the two groups. Infants in Group I spent $16.4 \%$ more time cooing or babbling than those in Group 2. This is one of the few areas in which the difference for the toddler group was greater than the infant group. Toddlers in Group I spent $33.4 \%$ more time babbling and talking to their caregivers than those in Group 2.

\section{DISCUSSION}

Results showed that caregiver training did not change the temporal context of the children in Group I when compared to Group 2, but the social context was changed significantly in terms of children in contact with others, particularly the primary caregivers. Both the percentage of time as well as the quality of time in terms of interaction using language was significantly greater for the infant and toddlers in Group I whose caregivers had received training.

\section{The temporal context or time use}

In this study infants in both Group I and Group 2 spent approximately $26 \%$ of their time in non-meaningful activity. This supports the findings of Tirella et al. ${ }^{10}$ who reported that children living in residential care facilities in Eastern Europe spend as much as 25\% of their awake-time in meaningless, developmentally inappropriate activity, such as walking around aimlessly, staring into space, or repetitive, stereotypical movements. In this study this finding was not replicated in the toddler groups where only 15\% of their time was spent in non-meaningful activity. This may be because they were mobile and spent time exploring and interacting with the environment even when a caregiver was not present. It was clear from the results that caregiver training had no effect on the amount of time infants or toddlers spent in meaningless activity and the training offered by Thusanani Children's Foundation was not useful for encouraging more active play amongst children in residential care.

Thus, a programme that aims at changing the activities infants and toddlers in residential care facilities engage in during the day requires not only caregiver training, but changes to the attitudes of management and to the structure of these facilities, as reported in other studies ${ }^{10}$.

What the training of the caregivers did achieve in terms of the children's temporal context was a significant reduction in the time the children spent alone. Tirella et al. ${ }^{10}$ reported disturbing statistics about the time infants and toddlers spent alone in Eastern European residential care facilities. This alone-time was assumed to be detrimental to normal cognitive, emotional and social development and this was the premise on which the caregiver training was based at the Thusanani Children's Foundation. Thus this aspect of the caregiver training can be viewed as effective as it did indeed significantly lower the amount of time infants and toddlers spent alone, particularly in the infant group. It is interesting to note that

the training made caregivers aware of the importance of spending time with the children and they began to apply this.

However, total time infants and toddlers spent alone still formed a large portion of their awake time even after their caregivers had received training. These results reflect that other factors may have played a role in how the children spend their time. This includes unfavourable caregiver-child ratios which mean that caregivers are not able to attend constantly to one child and encourage active participation in play. These ratios and expectations in the care facilities often necessitate strict routines for personal management activities and sleep. This allows busy caregivers who have many different tasks to complete in the day, including those only indirectly related to care giving (such as preparing meals, cleaning care giving rooms and folding laundry) the time nedded to complete all their tasks. Many caregivers (and their managers) see their "duties" as seeing to children's physical needs, but not necessarily their emotional or developmental needs and often there is limited understanding of the importance of including play activities in the daily schedule.

Finally, rotational shift work can also contribute to caregivers failing to form relationships with the children they care for, and can result in an apathy towards children's developmental and emotional needs. These factors are not unique to South Africa and have been reported all around the world. In Russia, one study reported that a child may have as many as 200 different caregivers before the age of two years due to the rotational shift work of caregivers ${ }^{4}$, while other studies reported the on the strict routines within institutions $s^{4,9,23}$. Interventions aimed at changing the things that children do every day have only been successful when the intervention included not only training, but also changes at management level as well as the overall structure of the institution ${ }^{4,18,24}$.

\section{Social context or interaction with others}

It is the change in social interaction within the personal management activity time and routines where the caregiver training appears to have been most effective and which has shown the most potential in terms of providing appropriate stimulation for the infants and toddlers. Here the greatest change was seen in the time spent in personal management and the number of interactions that took place during this time. The time spent in personal management activities with each child provided the ideal opportunity for encouraging social interaction without requiring the caregiver to spend extra time with any child in their already busy day. This allows the caregiver to use what little time she has with each child more effectively. Caregivers who had received training were much more likely to look at, touch, cuddle, hug and interact with the children in their care than those who had not received training. 
Caregivers who had received training showed far more responsivity in terms of the length of time they spent talking to their charges than those who had not received training. During observations they frequently looked at an infant during feeding, bathing and dressing, cooed and talked to the infant and responded to the infant's facial expressions and gurgling. They were also more likely to smile and interact reciprocally with the toddlers in their care and make personal management activities playful and stimulating. Caregivers who had not received training went about their duties in a more cold, clinical fashion. They were often seen propping a bottle in an infant's mouth and then chatting to another adult in the room, rather than paying attention to the infant. Toddlers did spend less time alone and demanded more attention than infants during personal management tasks as they are both more mobile and more verbal. However, interactions between caregivers who had not received training and their toddlers tended to focus on command-giving rather than reciprocal interactions.

\section{Implications of the study}

Early childhood is an important period as it forms the basis on which all later development is built. The long-term consequences of growing up in residential care can be particularly devastating because of the impairments which may develop in social and emotional abilities ${ }^{25,26}$. Professionals working in infant mental health must find ways of improving these outcomes that are more effective than a one-on-one, case-by-case approach that can only reach a limited number of children. Caregivers play an essential role in providing the kind of environment that is conducive to good early development.

As with previous studies ${ }^{20,21}$, the caregiver training programme focused predominantly on practicing skills within the existing work environment and the use of adult learning principles has been shown to be effective in changing the social context of the children in residential care in Johannesburg. This intervention was shown to carry over up to six to nine months after implementation with no further training and can therefore be considered as a satisfactory intervention to achieve change in some aspects of the temporal and the social context within these environments ${ }^{27}$.

The training in this study as suggested by the literature built on what caregivers already knew and did not try to include new activities or extra duties into the care-giving routine as this has proved unsuccessful in other countries $4,17,18$. However, a training programme that focuses on incorporating stimulation into existing routines and emphasises how interactions take place during existing activities as in this study did prove effective.

\section{Limitations of the study}

The measurement of the quality of the time use by infants and toddlers in residential care facilities was assessed in the very broad terms such as making eye-contact, touching the child in a purposeful manner or using language. Thus, this measurement is unable to detect more subtle changes in the quality of the time spent in interaction and the level of improvement may be understated The lack of assessment of the children developmental levels prior to the study also meant that assessment of change in their development could not be assessed.

The study was limited to three residential care facilities in the greater Johannesburg area had received caregiver training from Thusanani at the time of this study. These sites had also received training first as their managers had requested training from the foundation and were concerned about the developmental outcomes of the children resident at these facilities. This may have biased the sample and despite measures taken to ensure observation of a typical day at the facility, extraneous factors may have influenced how caregivers interact with the children in their care. The caregivers interaction may have been influenced by the presence of the observer and their knowledge of the purpose of the research study.

\section{CONCLUSION}

This study indicated that caregiver training did not change the temporal context or the activity profile related to the amount of time infant and toddlers in residential care facilities spent doing different activities. The children in both Group I and Group 2 spent a large percentage of time in non-meaningful activity, especially the infants. Caregiver training did however significantly reduce the time the children spent alone. The children's social context was influenced and changed by the extent of one-on-one contact with caregivers. The caregivers did not just spend more time with the children but used the time when they were usually in contact with the child during personal management activities to improve their interaction with infants and toddlers by increasing their language use and responding and encouraging language use in the infants and toddlers.

Caregiver training therefore has the potential to improve some temporal and social contexts or environments of infants and toddlers in residential care facilities and can be used as an intervention strategy by occupational therapists to facilitate development and prevent developmental delay particularly in the social context.

\section{REFERENCES}

I. Statistics South Africa. General Household Survey 2002 - 2014. Pretoria 2015.

2. Meiring M. The state of our children's homes. Unpublished masters disertaion, The University of the Witwatersrand: Johannesburg, 2008.

3. Rutter M, Sonuga-Barke EJ, Beckett C, Castle J, Kreppner J, Kumsta R, Schlotz W, Stevens S, Bell CA and Gunnar MR. Deprivationspecific psychological patterns: Effects of institutional deprivation. Monographs of the Society for Research in Child Development. 2010; 75 : i-253..

4. The St. Petersburg-USA Orphanage Research Team. The effects of early social-emotional and relationship experience on the development of young orphanage children. Monographs of the Society for Research in Child Development. 2008; 73: vii-295.

5. Pollak SD, Nelson CA, Schlaak MF, Roeber BJ, Wewerka SS, Wiik KL, Frenn KA, Loman MM and Gunnar MR. Neurodevelopmental effects of early deprivation in postinstitutionalized children. Child Development. 2010; 81: 224-236.

6. Fox SE, Levitt $P$ and Nelson CA. How the timing and quality of early experiences influence the development of brain architecture. Child Development. 2010; 81: 28-40

7. Moore T. Review of the Research Evidence on Early Child Development. In National Meeting on Early Childhood Systems. Melbourne: Centre for Community Child Health, 2002.

8. Meintjes, H., Moses, S., Berry, L and Mampane, R. Home truths: The phenomenon of residential care for children in a time of AIDS. Children's Institute (UCT), and the Centre for the Study of AIDS (UP). Cape Town, 2007

9. Swartz K. Achievement of Developmental milestones among Salvadorian orphans. Unpublished doctoral thesis, Virginia Polytechnic Institute and State University Virginia, 2009.

10. Tirella LG, Chan W, Cermak SA, Litvinova A, Salas KC and Miller LC. Time use in Russian baby homes. Child: Care, Health and Development. 2008; 34: 77-86.

II. Muhamedrahimov RJ, Palmov OI, Nikiforova NV, Groark CJ and McCall RB. Institution-based early intervention program. Infant Mental Health Journal. 2004; 25: 488-50I.

12. Giese $S$ and Dawes A. Child care, developmental delay and institutional practice. South African Journal of Psychology. 1999; 29: 17-22..

13. McCall RB, Fish LA, Groark CJ, Muhamedrahimov RJ, Palmov O and Nikiforova NV. The role of transitions to new age groups in the development of institutionalized children. Infant Mental Health Journal. 2012; 33: 421-429.

14. Scarr S. Developmental theories for the 1990s: Development and individual differences. Child development. 1992; 63: I-9.

15. Keller H. Development as the interface between biology and culture. A conceptualisation of early ontogenetic experiences. In: Keller $\mathrm{H}$, Poortinga $\mathrm{Y}$ and Schoelmerich A, (eds.). Between Culture and Biology. Cambridge: Cambridge University Press, 2002; I-3I. 
16. Shonkoff JP and Phillips DA. From Neurons to Neighborhoods: The Science of Early Childhood Programs. Committee on Integrating the Science of Early Childhood Development, Board on children, Youth, and Families. 2000.

17. Bakermans-Kranenburg MJ, van IJzendoorn $\mathrm{MH}$ and Juffer F. Earlier is better: A meta-analysis of 70 years of intervention improving cognitive development in institutionalized children. Monographs of the Society for Research in Child Development. 2008; 73: 279-93.

18. Groark CJ, McCall RB and Fish L. Characteristics of environments, caregivers, and children in three Central American orphanages. Infant Mental Health Journal. 20I I; 32: 232-250.

19. Wright AC, Lamsal D, Ksetree M, Sharma A and Jaffe K. From maid to mother: Transforming facilities, staff training, and caregiver dignity in an institutional facility for young children in Nepal. Infant Mental Health Journal. 2014; 35: 132-143.

20. Groark CJ, Muhamedrahimov RJ, Palmov OI, Nikiforova NV and McCall RB. Improvements in early care in Russian orphanages and their relationship to observed behaviors. Infant Mental Health Journal. 2005; 26: 96-109.

21. Groark CJ and McCall RB. Implementing changes in institutions to improve young children's development. Infant Mental Health Journal. 20II; 32: 509-525..

22. Kielhofner G. Research in Occupational Therapy: Methods of Inquiry for Enhancing Practice. Philadelphia: F.A. Davis Company, 2006.

23. Daunhauer LA, Bolton A and Cermak SA. Time-use patterns of young children institutionalized in Eastern Europe. OTJR: Occupation, Participation and Health. 2005; 25: 33-40.

24. Berument SK. Environmental enrichment and caregiver training to support the development of birth to 6-year-olds in Turkish orphanages. Infant Mental Health Journal. 2013; 34: I89-20I.

25. Fox NA, Almas AN, Degnan KA, Nelson CA and Zeanah CH. The effects of severe psychosocial deprivation and foster care intervention on cognitive development at 8 years of age: findings from the Bucharest Early Intervention Project. Journal of Child Psychology and Psychiatry. 20II; 52: 919-928.

26. Beckett C, Maughan B, Rutter M, Castle J, Colvert E, Groothues C, Kreppner J, Stevens S, O'Connor TG and Sonuga-Barke EJ. Do the effects of early severe deprivation on cognition persist into early adolescence? Findings from the English and Romanian adoptees study. Child Development. 2006; 77(3): 696-7II.

27. Taneja V, Aggarwal R, Beri RS and Puliyel JM. Not by bread alone project: a 2-year follow-up report. Child: care, Health And Development. 2005; 31 (6): 703-6.

Corresponding Author

Lyndsay Koch

Lyndsay.Koch@wits.ac.za 